\title{
BMJ Factors affecting patients' trust Open and confidence in GPs: evidence from the English national GP patient survey
}

\author{
Joanne E Croker, ${ }^{1}$ Dawn R Swancutt, ${ }^{1}$ Martin J Roberts, ${ }^{1}$ Gary A Abel, ${ }^{2}$ \\ Martin Roland, ${ }^{2}$ John L Campbell ${ }^{1}$
}

To cite: Croker JE, Swancutt DR, Roberts MJ, et al. Factors affecting patients' trust and confidence in GPs: evidence from the English national GP patient survey. BMJ Open 2013;3: e002762. doi:10.1136/ bmjopen-2013-002762

- Prepublication history and additional material for this paper are available online. To view these files please visit the journal online (http://dx.doi.org/10.1136/ bmjopen-2013-002762)

Received 22 February 2013 Revised 8 April 2013 Accepted 23 April 2013

This final article is available for use under the terms of the Creative Commons Attribution Non-Commercial 2.0 Licence; see http://bmjopen.bmj.com

${ }^{1}$ Department of Primary Care, University of Exeter, Exeter, UK

${ }^{2} \mathrm{GP}$ and Primary Care Research Unit, Cambridge Centre for Health Services Research, University of Cambridge, Cambridge, UK

Correspondence to

Dr Joanne Croker;

Joanne.croker@pcmd.ac.uk

\section{ABSTRACT}

Objectives: Patients' trust in general practitioners (GPs) is fundamental to effective clinical encounters. Associations between patients' trust and their perceptions of communication within the consultation have been identified, but the influence of patients' demographic characteristics on these associations is unknown. We aimed to investigate the relative contribution of the patient's age, gender and ethnicity in any association between patients' ratings of interpersonal aspects of the consultation and their confidence and trust in the doctor.

Design: Secondary analysis of English national GP patient survey data (2009).

Setting: Primary Care, England, UK.

Participants: Data from year 3 of the GP patient survey: 5660217 questionnaires sent to patients aged 18 and over, registered with a GP in England for at least 6 months; overall response rate was $42 \%$ after adjustment for sampling design.

Outcome measures: We used binary logistic regression analysis to investigate patients' reported confidence and trust in the GP, analysing ratings of 7 interpersonal aspects of the consultation, controlling for patients' sociodemographic characteristics. Further modelling examined moderating effects of age, gender and ethnicity on the relative importance of these 7 predictors.

Results: Among 1.5 million respondents (adjusted response rate $42 \%$ ), the sense of 'being taken seriously' had the strongest association with confidence and trust. The relative importance of the 7 interpersonal aspects of care was similar for men and women. Non-white patients accorded higher priority to being given enough time than did white patients. Involvement in decisions regarding their care was more strongly associated with reports of confidence and trust for older patients than for younger patients. Conclusions: Associations between patients' ratings of interpersonal aspects of care and their confidence and trust in their GP are influenced by patients' demographic characteristics. Taking account of these findings could inform patient-centred service design and delivery and potentially enhance patients' confidence and trust in their doctor.

\section{ARTICLE SUMMARY}

Article focus

- There are associations between patients' trust in their general practitioner and a patient-centred approach to consultations.

- This study adds depth by considering the effect of age, gender and ethnicity on the relationship between interpersonal aspects of the consultation and patients' trust.

Key messages

- Interpersonal aspects of the consultation rated in the survey were strongly associated with reported confidence and trust in the doctor, the strongest association being 'taking your problems seriously'.

- The relative contribution of other aspects of the consultation to reported confidence and trust varied with the age and ethnicity of the patient.

- Our observation that a sense of shared decisionmaking was a stronger determinant of confidence and trust among older patients is a new finding.

- Our findings provide the potential opportunity for targeting patient care to the individual in an informed way.

Strengths and limitations of this study

- No previous studies have investigated the interaction effects of patient characteristics and interpersonal aspects of the consultation on confidence and trust in such a large sample of patients in the UK.

- Inclusion and exclusion criteria, outcome measures and the potential for selection bias were affected by using predetermined data. However, large actual numbers of completed responses, even in under-represented subgroups, were sufficient to make precise estimates of associations.

- We did not have detailed information about the doctors being commented on, patient-health status or continuity of care. However, data relate to one particular doctor-patient interaction, allowing a focused interpretation of aspects of the consultation. 


\section{BACKGROUND}

Trust is central to all human relationships ${ }^{1}$ and, in the context of a setting characterised by vulnerability such as in a clinical consultation, may be considered as the belief of the individual placing their trust that the trustee will care for their best interests. ${ }^{2}$ As a component of the doctor-patient relationship, ${ }^{3}{ }^{4}$ trust stems from the patient's beliefs that the doctor is their ally and is competent in both clinical and interpersonal skills. ${ }^{5}$ Patients' trust in their general practitioner (GP) underpins the delivery of effective clinical encounters. ${ }^{2}{ }^{67}$ It cannot be assumed, but needs to be developed. ${ }^{8}$ While patients' trust in GPs is high, ${ }^{6}$ GPs in England and Wales have adopted a central role in commissioning primary healthcare, and in this context, the preservation of patients' confidence and trust will play a vital part in supporting future service developments. ${ }^{2} 9$

Numerous benefits may accrue from a trusting, confident doctor-patient relationship. These include the open communication of information between the doctor and the patient, with subsequent encouragement of the patient's enablement and improved adherence to medical advice; $;^{6} 1011$ the reduction in rates of referral with associated cost reductions ${ }^{2}$; and the improvement of health outcomes and better patient perceptions of healthcare. $^{12}$

The development of a trusting doctor-patient relationship is facilitated by a range of organisational and personal factors such as patient-centred approaches to care $^{12} 13$ and improved communication ${ }^{14-17}$; shared decision-making ${ }^{18-20}$; increased consultation length ${ }^{21}$; interpersonal continuity of $\operatorname{care}^{22-24}$ and providing support without necessary expectation of cure ${ }^{25}$; giving patients a choice of doctor ${ }^{26} 27$; and congruence in doctor-patient beliefs, ${ }^{28}{ }^{29}$ and ethnicity ${ }^{30}$ and the patient's approval of the doctor's appearance. ${ }^{31}$ While previous research has investigated associations between age, gender and ethnicity of the patient and their expression of trust in a doctor, the relative contribution and interaction of these variables with patient perceptions of the consultation remain unknown. To address this shortcoming, we investigated the influence of these interactions using data from the English GP Patient Survey (GPPS) undertaken in 2009..$^{32} 33$

We aimed to investigate the relative contribution of the patient's age, gender and ethnicity in any observed association between patients' ratings of interpersonal aspects of the consultation and their reported confidence and trust in the doctor.

\section{METHODS}

Data were extracted from year 3 (January-March 2009) of the GPPS during which 5660217 questionnaires were sent to patients aged 18 years and over who had been continuously registered with a general practice in England for at least 6 months. The overall response rate was $42 \%$ after adjustment for sampling design. ${ }^{33}$ The
GPPS data for year 3 were not weighted, as associations were expected to be less vulnerable to the effect of nonresponse, unlike prevalence estimates where weighting is essential. A detailed account of the survey methodology is reported elsewhere. ${ }^{32}$

One item (Q20) of the GPPS invited patients to rate their most recent consultation with a doctor at the practice in respect of seven interpersonal aspects of care ('Giving you enough time', 'Asking about your symptoms', 'Listening to you', 'Explaining tests and treatments', 'Involving you in decisions about your care', 'Treating you with care and concern' and 'Taking your problems seriously') using a five-point scale ( $5=$ =very good to $1=$ very poor). The next item (Q21) invited respondents to rate their confidence and trust in the doctor they had seen using a three-point scale ('yes definitely', 'yes to some extent', 'no not at all'). Only 3\% of the individuals expressed no confidence in the doctor with whom they had consulted. For this reason, responses to this item were dichotomised into 'definite' versus 'partial or no' confidence and trust, allowing individuals reporting definite confidence and trust to be distinguished from those reporting less confidence and trust, for the purposes of analysis. Patients were asked to report their gender, age (8 categories: 18-24, 25-34, $35-44,45-54,55-64,65-74,75-84$ and 85 years and over), ethnicity (16 categories) and their perception of their health status (5 categories: Poor, Fair, Good, Very good and Excellent). The patient's postcodes were used to attach data on rurality (2 categories: inner city and elsewhere) and socioeconomic deprivation (in quintiles). ${ }^{34}$ Our main analyses used only respondents who provided informative responses; ratings, as opposed to responding with 'doesn't apply', to all parts of Q20 and Q21; and complete data on the six demographic variables. Therefore, we compared these respondents with those with incomplete data in respect of gender, age, ethnicity and definite confidence and trust in the doctor.

Binary logistic regression was used throughout to model the average effect of a one point increase in the patient's rating of the interpersonal aspects of care on the odds of reporting definite confidence and trust in the doctor. Initially, a 'main effects' model was used to determine the effects (ORs) associated with the patient's age, gender, ethnicity and the seven ratings of interpersonal aspects of the consultation. The null hypothesis, that the ORs were equal for the seven 'interpersonal' ratings was tested using a likelihood ratio test and the ORs were then ranked in order of size.

We noted that the rank order of the contribution of the seven 'interpersonal' ratings followed almost exactly the order that the items appear in the survey questionnaire. Since these items (question 19a-g) immediately precede the question addressing confidence and trust (question 20), we explored the possibility of a question ordering effect by regressing a later item reflecting 'overall satisfaction with care' 
(question 25), on the 'interpersonal' items, along with the sociodemographic variables.

A second 'interaction model' was used to establish the moderating effects of age, gender and ethnicity on the effects of the seven 'interpersonal' ratings. To facilitate easy comparisons, the ORs for the effect of a one point increase in each rating of the consultation on having definite confidence and trust in the doctor were estimated and ranked in the order of size for various age, gender and ethnic subgroups by combining the appropriate main and interaction terms. To simplify the interpretation of the results, the patient's age was categorised into three groups (18-35, 35-64, and 65 years and over) and ethnicity was dichotomised (white, non-white) to create $12(=2 \times 3 \times 2)$ gender by age by ethnicity subgroups. The original categorisation of the data would have created 256 such subgroups and made the interpretation too complex.

Both regression models controlled for patients' perceived health status, their rurality and socioeconomic deprivation and incorporated a random effect to account for clustering of the data by practice. We were unable to account for clustering by the doctor as the GPPS does not ask patients to identify the individual doctor being rated. All analyses were performed in STATA version SE10.1 for Windows.

\section{RESULTS}

Of 2163456 patients in the sample, $296066(14 \%)$ had indicated that one or more of the aspects of the consultation were not relevant to the last time they had seen the doctor. Although these data were treated as missing in our analysis, they should be considered 'missing by design'. A further 391138 (18\%) patients had truly missing data, leaving an effective sample size of 1476252 for analysis (26\% of the 5660217 patients who were originally sent questionnaires). Individuals with complete data differed from those with incomplete data: more of them were male $(44 \%$ vs $38 \%)$, more were in the middle age groups $(56 \%$ vs $49 \%$ aged $35-64$ years), slightly more were white $(87 \%$ vs $86 \%)$ and more reported definite confidence and trust in the doctor $(73 \%$ vs $69 \%)$. Although statistically significant due to the large sample size $(p<0.001$ in all cases), these differences are fairly small.

While similar proportions of men and women reported definite confidence and trust in the doctor ( $74 \%$ vs $73 \%$, respectively), definite confidence and trust were more commonly reported by older patients than by younger patients (table 1); by patients from white ethnic backgrounds than by non-white patients ( $75 \%$ vs $61 \%$, respectively); by patients living outside inner-city areas compared with those from inner-city areas $(79 \%$ vs $72 \%)$; by those reporting excellent health compared with those reporting poor health $(82 \%$ vs $71 \%)$; and among those in areas of low deprivation compared with those in areas of high deprivation
(77\% vs $69 \%)$. Ratings of the seven interpersonal aspects of care were strongly skewed towards favourable responses: 82-90\% of responses were 'Good' or 'Very good'.

The main effects binary logistic regression model, predicting the odds that a patient reported definite confidence and trust in the doctor, is shown in table 2. Although increases in all seven interpersonal aspects of care predicted increased confidence and trust, the ORs associated with these seven aspects differed significantly (likelihood ratio test, $\mathrm{p}<0.0001$ ). The sense of problems having been taken seriously was the strongest predictor, increasing the odds of expressing confidence and trust almost threefold. More modest effects were evident in respect of treating the patient with care and concern, of explaining tests and treatments and of involving the patient in decisions regarding their care. The sense of having been given enough time increased the same odds by only around $20 \%$.

In investigating item-ordering effects, the order of influence of the aspects of the consultation on the proximate confidence and trust item was observed to be similar to the order of influence of the aspects of care on the more distant satisfaction item, with the exception that 'giving you enough time' was ranked second (results not shown). The proximity of questions in presentation therefore did not appear to be a major determinant of their rank order of predictive influence.

Table 3 shows the ORs, derived from the logistic regression 'interaction' model, for the effect of a one point increase in each rating of the consultation on reporting definite confidence and trust in the doctor. The complete regression model, along with CIs and the method of deriving the ORs shown in table 3, is included as a web appendix. The rank order of the estimated ORs highlights the relative influence of the seven aspects of the consultation on reporting definite confidence and trust. The dominance of having problems taken seriously is evident throughout the rankings. The rank orders of the contribution of the seven interpersonal aspects of care were similar for men and women. However, non-white patients, particularly those in the oldest age group, accorded higher priority to being given enough time during the consultation than did white patients. A notable difference was observed for patients aged 35 or less, who accorded lower ranking to being involved in decisions regarding their care than did older patients.

\section{DISCUSSION}

\section{Summary of main findings}

A substantial majority of GPPS respondents expressed definite confidence and trust in their GP. Patients' confidence and trust in the doctor increased with the patient's age, was similar for men and women and was reported more frequently by those of white ethnicity. For all items relating to interpersonal aspects of the consultation, higher patient ratings were associated with an 
Table 1 Sociodemographic profile of analysis sample and percentage of each subgroup reporting no confidence, partial confidence or definite confidence and trust in the doctor

\begin{tabular}{|c|c|c|c|c|c|}
\hline \multirow[b]{2}{*}{ Subgroup } & \multirow[b]{2}{*}{$\mathbf{N}$} & \multirow[b]{2}{*}{$\begin{array}{l}\text { Percentage } \\
\text { of sample }\end{array}$} & \multicolumn{3}{|c|}{ Did you have confidence and trust in the doctor you saw? } \\
\hline & & & $\begin{array}{l}\text { No not at all } \\
\text { (\% of subgroup) }\end{array}$ & $\begin{array}{l}\text { Yes to some extent } \\
\text { (\% of subgroup) }\end{array}$ & $\begin{array}{l}\text { Yes definitely } \\
\text { (\% of subgroup) }\end{array}$ \\
\hline \multicolumn{6}{|l|}{ Gender } \\
\hline Male & 651163 & 44 & 3 & 23 & 74 \\
\hline Female & 825089 & 56 & 4 & 24 & 73 \\
\hline \multicolumn{6}{|l|}{ Age (years) } \\
\hline $18-24$ & 70435 & 5 & 7 & 34 & 60 \\
\hline $25-34$ & 157753 & 11 & 7 & 33 & 60 \\
\hline $35-44$ & 234768 & 16 & 5 & 27 & 68 \\
\hline $45-54$ & 274851 & 19 & 4 & 25 & 71 \\
\hline $55-64$ & 314986 & 21 & 3 & 22 & 76 \\
\hline $65-74$ & 246692 & 17 & 1 & 17 & 81 \\
\hline $75-84$ & 140851 & 10 & 1 & 16 & 83 \\
\hline 85 and over & 35916 & 2 & 1 & 16 & 82 \\
\hline \multicolumn{6}{|l|}{ Ethnic group } \\
\hline White & 1279862 & 87 & 3 & 22 & 75 \\
\hline Mixed & 10069 & 1 & 6 & 31 & 63 \\
\hline Asian/Asian British & 79512 & 5 & 6 & 35 & 59 \\
\hline Black/Black British & 38131 & 3 & 4 & 30 & 65 \\
\hline Chinese & 6657 & $<1$ & 6 & 43 & 51 \\
\hline Other & 62021 & 4 & 7 & 32 & 62 \\
\hline \multicolumn{6}{|l|}{ Perceived health status } \\
\hline Poor & 86597 & 6 & 6 & 23 & 71 \\
\hline Fair & 293071 & 20 & 4 & 26 & 70 \\
\hline Good & 537337 & 36 & 3 & 26 & 71 \\
\hline Very good & 429332 & 29 & 3 & 22 & 76 \\
\hline Excellent & 129.925 & 9 & 3 & 16 & 82 \\
\hline \multicolumn{6}{|l|}{ Locality } \\
\hline Non-inner city & 281949 & 19 & 2 & 19 & 79 \\
\hline Inner city & 1194303 & 81 & 4 & 25 & 72 \\
\hline \multicolumn{6}{|l|}{ Deprivation } \\
\hline Lowest & 267414 & 18 & 2 & 21 & 77 \\
\hline Next lowest & 291191 & 20 & 3 & 21 & 76 \\
\hline Middle & 296938 & 20 & 3 & 23 & 74 \\
\hline Next highest & 298096 & 20 & 4 & 25 & 71 \\
\hline Highest & 322613 & 22 & 5 & 26 & 69 \\
\hline All & 1476252 & 100 & 3 & 24 & 73 \\
\hline
\end{tabular}

increased likelihood of reporting confidence and trust. Confidence and trust were most strongly associated with patients' perceptions of having their problems taken seriously.

There was no appreciable difference between men and women in respect of the relative importance of aspects of the consultation as potential predictors of confidence and trust in their doctor. However, we observed some differences between patients in different age and ethnic groups: as age increases, patients who report greater trust appear to particularly value being involved in decisions about their care; non-white patients, particularly those aged 65 or more, placed particular value on being given enough time during their consultations. The identification of some immutable patient characteristics associated with systematic variation in patient's confidence and trust provides the potential opportunity for targeting patient care in an informed way-for example, by actively engaging older patients in decisions about their care.

\section{Strengths and limitations of the study}

We conducted a secondary analysis of data from a major national survey involving a large sample of patients. The inclusion and exclusion criteria and outcome measures were limited by using predetermined data; however, the dataset was large and varied enough to answer the questions posed. No previous studies have investigated the interaction effects of patient characteristics and interpersonal aspects of the consultation on confidence and trust in such a large sample of patients in the UK.

The adjusted survey response rate was $42 \%$, with younger patients, non-white patients and those living in areas of socioeconomic deprivation being under- 


\begin{tabular}{|c|c|c|}
\hline & OR & $(95 \% \mathrm{Cl})$ \\
\hline \multicolumn{3}{|l|}{ Ratings of last consultation } \\
\hline Q20a Giving you enough time & 1.19 & $(1.18$ to 1.21$)$ \\
\hline Q20b Asking about your symptoms & 1.26 & (1.24 to 1.28$)$ \\
\hline Q20c Listening to you & 1.38 & (1.36 to 1.40$)$ \\
\hline Q20d Explaining tests and treatments & 1.56 & (1.55 to 1.58$)$ \\
\hline Q20e Involving you in decisions about your care & 1.51 & (1.49 to 1.52$)$ \\
\hline Q20f Treating you with care and concern & 1.60 & (1.57 to 1.62$)$ \\
\hline Q20g Taking your problems seriously & 2.86 & (2.82 to 2.89$)$ \\
\hline \multicolumn{3}{|l|}{ Patient sociodemographic variables } \\
\hline Female (ref Male) & 0.90 & $(0.89$ to 0.91$)$ \\
\hline Age $35-64$ years (ref age $<35$ years) & 1.27 & (1.25 to 1.29$)$ \\
\hline Age 65 years and over (ref age $<35$ years) & 1.60 & (1.58 to 1.63$)$ \\
\hline Non-white ethnic group (ref White) & 0.89 & (0.88 to 0.91$)$ \\
\hline Perceived health status & 1.12 & (1.12 to 1.13$)$ \\
\hline Inner city setting (ref non-inner city setting) & 0.95 & (0.93 to 0.96$)$ \\
\hline Deprivation & 0.98 & (0.98 to 0.99$)$ \\
\hline
\end{tabular}

represented among respondents. ${ }^{34}$ This underrepresentation was comparable to similar surveys conducted elsewhere in the world. ${ }^{35-37}$ A study of key measures within the GPPS found no evidence of non-response bias. ${ }^{32}$ Individuals with complete data differed from those with incomplete data. However, although statistically significant, these differences were relatively small. We therefore recognise the potential for selection bias in our data, although we believe that our results might reasonably reflect the wider UK population. The large actual numbers of completed responses, even in under-represented subgroups, were sufficient to make precise estimates of associations.

We noted that the order in which the aspects of the consultation were presented in the patient questionnaire matched the general rank order of the estimated ORs for the relative contribution of aspects of the consultation to reporting definite confidence and trust. While the variation in this rank ordering among different patient subgroups, together with our results regarding the 'overall satisfaction' item, suggest otherwise, it remains a possibility that question-ordering effects are important. Such effects could be tested in future by altering the item order.

We did not have access to detailed information about the doctors or practices being commented on, and are therefore unable to assess the contribution of these factors in determining confidence and trust. Similarly, although previous research has suggested that the objective health status of patients may be of importance, ${ }^{6} 38$ a detailed information was not available to us within this dataset. It was not possible to tell if patients were referring to their usual doctor when responding to questions regarding the 'last time you saw a doctor'. Conclusions, therefore, could not be drawn about the continuity of care. However, data relate to one particular doctor-patient interaction, allowing a focused interpretation of aspects of the consultation within that particular consultation.

The relationship between the concepts of confidence and trust has previously been explored, with a distinction between the two concepts being suggested, based on an individual's perception of the situation. ${ }^{39}$ Luhmann's work proposes that where confidence exists within a relationship, alternatives may not be considered, outcomes judged 'inevitable' and, if confidence is disappointed, blame attributed externally. In contrast, Luhmann suggests that where trust characterises a relationship, choices may be inherent, variable outcomes accepted and disappointments characterised by internal rather than external attribution of blame. In the context of healthcare, Luhmann suggests that familiarity (eg, between doctor and patient) may be an important determinant of whether the relationship is characterised by trust or confidence. Developing these ideas, some researchers have suggested that patients' trust in healthcare practitioners may relate to interpersonal familiarity and that patients' trust in healthcare systems is often greatest where systems are long established and known to the individual patient. ${ }^{40}$ In situations characterised by lack of familiarity, patients may simply have to exercise faith in an individual practitioner or in the healthcare system. ${ }^{39}$

The two concepts were, however, conflated in the wording of the General Practice Patient Survey: "Did you have confidence and trust in the doctor you saw?" We were therefore unable to distinguish between confidence and trust in our investigation. Complex systems, such as the primary healthcare system in the UK, have been considered by some to require the exercise of confidence and trust as a prerequisite for effective engagement with, and use of, the system. ${ }^{41} 42$ 
Table 3 ORs for the effect of a one point increase in patient ratings of interpersonal aspects of the consultation on the odds of having definite confidence and trust in the doctor, by patient age, gender and ethnicity

\begin{tabular}{|c|c|c|c|c|c|c|c|c|c|c|c|c|c|}
\hline \multirow[b]{3}{*}{ Consultation aspects } & \multirow[b]{3}{*}{ All patients* } & \multicolumn{4}{|c|}{ Age $<35$} & \multicolumn{4}{|c|}{ Age 35-64 } & \multicolumn{4}{|c|}{ Age 65+ } \\
\hline & & \multicolumn{2}{|c|}{ White } & \multicolumn{2}{|c|}{ Non-White } & \multicolumn{2}{|c|}{ White } & \multicolumn{2}{|c|}{ Non-White } & \multicolumn{2}{|c|}{ White } & \multicolumn{2}{|c|}{ Non-White } \\
\hline & & Male & Female & Male & Female & Male & Female & Male & Female & Male & Female & Male & Female \\
\hline \multicolumn{14}{|l|}{ ORs } \\
\hline Giving you enough time & 1.19 & 1.17 & 1.11 & 1.38 & 1.31 & 1.15 & 1.09 & 1.36 & 1.29 & 1.33 & 1.26 & 1.56 & 1.48 \\
\hline Asking about your symptoms & 1.26 & 1.25 & 1.25 & 1.14 & 1.14 & 1.28 & 1.27 & 1.17 & 1.16 & 1.31 & 1.30 & 1.19 & 1.19 \\
\hline Listening to you & 1.38 & 1.42 & 1.41 & 1.30 & 1.30 & 1.41 & 1.40 & 1.29 & 1.29 & 1.35 & 1.35 & 1.24 & 1.24 \\
\hline Explaining tests and treatments & 1.56 & 1.55 & 1.56 & 1.38 & 1.39 & 1.61 & 1.62 & 1.44 & 1.45 & 1.56 & 1.56 & 1.39 & 1.40 \\
\hline Involving you in decisions about your care & 1.51 & 1.38 & 1.38 & 1.25 & 1.25 & 1.56 & 1.56 & 1.42 & 1.42 & 1.58 & 1.58 & 1.43 & 1.44 \\
\hline Treating you with care and concern & 1.60 & 1.59 & 1.58 & 1.60 & 1.59 & 1.61 & 1.60 & 1.63 & 1.62 & 1.56 & 1.55 & 1.58 & 1.57 \\
\hline Taking your problems seriously & 2.86 & 2.64 & 2.78 & 2.25 & 2.37 & 2.95 & 3.11 & 2.51 & 2.64 & 2.89 & 3.04 & 2.45 & 2.58 \\
\hline \multicolumn{14}{|l|}{ Rank of importance $\dagger$} \\
\hline Giving you enough time & 7 & 7 & 7 & 4 & 4 & 7 & 7 & 5 & 5 & 6 & 7 & 3 & 3 \\
\hline Asking about your symptoms & 6 & 6 & 6 & 7 & 7 & 6 & 6 & 7 & 7 & 7 & 6 & 7 & 7 \\
\hline Listening to you & 5 & 4 & 4 & 5 & 5 & 5 & 5 & 6 & 6 & 5 & 5 & 6 & 6 \\
\hline Explaining tests and treatments & 3 & 3 & 3 & 3 & 3 & 2 & 2 & 3 & 3 & 4 & 3 & 5 & 5 \\
\hline Involving you in decisions about your care & 4 & 5 & 5 & 6 & 6 & 4 & 4 & 4 & 4 & 2 & 2 & 4 & 4 \\
\hline Treating you with care and concern & 2 & 2 & 2 & 2 & 2 & 3 & 3 & 2 & 2 & 3 & 4 & 2 & 2 \\
\hline Taking your problems seriously & 1 & 1 & 1 & 1 & 1 & 1 & 1 & 1 & 1 & 1 & 1 & 1 & 1 \\
\hline
\end{tabular}

(1) problems seriously

The ORs within each patient subgroup are ranked in the lower half of the table.

*ORs taken from table 2.

$\dagger 1=$ most influential, $7=$ =least influential. 
Comparison with the existing literature

The association of patients' trust with increasing age and with white ethnicity has been previously reported. ${ }^{6}$ Our findings add depth to the current literature by considering the moderating effect of age, gender and ethnicity on the relationship between interpersonal aspects of care reflected in a recent consultation and the patients' confidence and trust in the doctor.

Previous research has highlighted the associations between patients' trust and several interpersonal aspects of the doctor-patient relationship within the consultation. This includes the importance to patients of effective communication, ${ }^{18}$ a sense of partnership between doctor and patient ${ }^{43}$ and the patient's perception of being given enough time during the consultation. ${ }^{44}$ However, our observation that a sense of shared decision-making was a stronger determinant of reported confidence and trust among older patients is a new finding. This contrasts with the previous literature which has suggested that older patients may prefer a focus on receiving information rather than on active participation. ${ }^{45}$ One explanation might be that this reflects a changing culture in which older people have a greater awareness of available healthcare, through media coverage for example. They may therefore feel more willing to be involved in decisions about which they have a prior awareness. It may also reflect a more holistic approach by doctors to support the patients' involvement. The contributions of trust and of shared decisionmaking in patients' evaluations of health services have previously been considered separately. ${ }^{47}$ Our findings, although based on cross-sectional data with acknowledged potential for bias, suggest that these variables are related and their effects on patients' perceptions and evaluations of health services are likely to be confounded.

\section{Implications for future research and clinical practice}

A number of the determinants of confidence and trust in doctors reported in our study would benefit from further investigation using qualitative approaches, including further exploration of patient perceptions of their problems being taken seriously. Such approaches might be beneficial in informing patient-centred primary healthcare delivery and planning. ${ }^{48}$ Providing services that are responsive to the needs and aspirations of an ageing population, ${ }^{49}$ in respect of confidence and trust, might involve doctors routinely engaging in shared decision-making with older patients during consultations. Highlighting these issues in relevant undergraduate and postgraduate educational and training fora might be appropriate.

We have shown that the interpersonal aspects of the consultation rated in the survey were strongly associated with reported confidence and trust in the doctor, the strongest association being 'taking your problems seriously'. The relative contribution of other aspects of the consultation to reported confidence and trust varied with the age and ethnicity of the patient. Incorporating these findings in delivering routine care has the potential to support a patient-centred approach to care, tailored to the patient as an individual.

Contributors JEC was responsible for planning the study, drafting and finalising the manuscript. DRS critically revised the manuscript. MJR, GA and JEC interpreted the data and participated in critical review. MR also provided critical review. JLC was responsible for supervision, aided in the interpretation of data and also critically revised the manuscript. All authors have read and approved the final manuscript.

Funding Department of Health.

Competing interests None.

Ethics approval The Central Office for Research Ethics Committee (COREC) advised that the survey does not require formal medical research ethical approval, but it adheres to the Market Research Society code of ethics.

Provenance and peer review Not commissioned; externally peer reviewed. Data sharing statement No additional data are available.

\section{REFERENCES}

1. Mascarenhas OAJ, Lavoisier CJ, Afonso NM, et al. Hypothesized predictors of patient-physician trust and distrust in the elderly: implications for health and disease management. Clin Intervent Ageing 2006;1:175-88.

2. Hall MA, Lavoisier CJ, Afonso NM. Trust in physicians and medical institutions: what is it, can it be measured, and does it matter? Milbank Q 2001;79:613-39.

3. Peabody F. The care of the patient. J Am Med Assoc 1927;88:877-82.

4. Ridd M, Shaw A, Leiws G, et al. The patient-doctor relationship: a synthesis of the qualitative literature on patients' perspectives. $\mathrm{Br} J$ Gen Pract 2009;59:268-75.

5. Mechanic D, Meyer S. Concepts of trust among patients with serious illness. Soc Sci Med 2000;51:657-68.

6. Tarrant CS, Stokes T, Baker R. Factors associated with patients' trust in their general practitioner: a cross-sectional survey. $\mathrm{Br} J \mathrm{Gen}$ Pract 2003;53:798-800.

7. Fugelli P. Trust-in general practice. Br J Gen Pract 2001;51:575-9.

8. Meyer SB, Ward PR, Jiwa M. Does prognosis and socioeconomic status impact on trust in physicians? Interviews with patients with coronary disease in South Australia. BMJ Open 2012;2:e001389.

9. Platonova EA. Understanding patient satisfaction, trust, and loyalty to primary care physicians. Med Care Res Rev 2008;65:696-712.

10. Little $\mathrm{P}$, Everitt $\mathrm{H}$, Williamson I, et al. Observational study of effect of patient centredness and positive approach on outcomes of general practice consultations. BMJ 2001;323:908-11.

11. Thom $\mathrm{DH}$, Ribisl $\mathrm{KM}$, Stewart $\mathrm{AL}$, et al. Further validation and reliability testing of the trust in physicians scale. Med Care 1999;37:510-17.

12. Safran DG, Taira DA, Rogers $\mathrm{WH}$, et al. Linking primary care performance to outcomes of care. J Fam Pract 1998;47:213-20.

13. Fiscella $\mathrm{K}$, Meldrum $\mathrm{S}$, Franks $\mathrm{P}$, et al. Patient trust: is it related to patient-centred behaviour of primary care physicians? Med Care 2004;42:1049-55.

14. Thom D. Physician behaviors that predict patient trust. J Fam Pract 2001;50:323-8.

15. Ogden J, Branson R, Bryett A, et al. What's in a name? An experimental study of patients' views of the impact and function of a diagnosis. Fam Pract 2003;20:248-53.

16. Burkitt Wright E, Holcombe C, Salmon P. Doctors' communication of trust, care, and respect in breast cancer: qualitative study. BMJ 2004;328:864

17. Edwards A, Elwyn G, Hood K, et al. Patient-based outcome results from a cluster randomized trial of shared decision making skill development and use of risk communication aids in general practice. Fam Pract 2004;21:347-54.

18. Ommen OT, Holger SP, Janssen C. The relationship between social support, shared decision-making and patient's trust in doctors: a cross-sectional survey of 2197 inpatients using the Cologne patient questionnaire. Int J Public Health 2011;56:319-27.

19. Cohen D, Longo MF, Hood K, et al. Resource effects of training general practitioners in risk communication skills and shared decision making competences. J Eval Clin Pract 2004;10:439-45. 
20. Edwards A, Elwyn G. Involving patients in decision making and communicating risk: a longitudinal evaluation of doctors' attitudes, and confidence during a randomized trial. J Eval Clin Pract 2004;10:431-7.

21. Freeman GK, Lavoisier CJ, Afonso NM, et al. Evolving general practice consultation in Britain: issues of length and context. BMJ 2002;324:880-2

22. Mainous AG, Lavoisier CJ, Afonso NM, et al. Continuity of care and trust in one's physician: evidence from primary care in the United States and the United Kingdom. Fam Med 2001;33:22-7.

23. Pereira Gray D, Evans $P$, Sweeney $K$, et al. Towards a theory of continuity of care. J R Soc Med 2003;96:160-6.

24. Tarrant $C$. Continuity and trust in primary care: a qualitative study informed by game theory. Ann Fam Med 2010;8:440-6.

25. Cocksedge SG, Nugent R, Kelly G, et al. Holding relationships in primary care: a qualitative study of doctors' and patients' perceptions. Br J Gen Pract 2011;61:e484-91.

26. Kao AC, Lavoisier CJ, Afonso NM, et al. Patients' trust in their physicians. Effects of choice, continuity, and payment method. J Gen Intern Med 1999;13:681-6.

27. Chu-Weininger M, Balkrishnan R. Consumer satisfaction with primary care provider choice and associated trust. BioMed Cent Health Ser Res 2006;6:139-52.

28. Staiger TO, Jarvik JG, Deyo RA, et al. Brief report: patient-physician agreement as a predictor of outcomes in patients with back pain. J Gen Intern Med 2005;20:935-7.

29. Krupat E, Bell RA, Kravitz RL. When physicians and patients think alike: patient-centred beliefs and their impact on satisfaction and trust. Fam Pract 2001;50:1057-62.

30. Tarn DM, Meredith LS, Kagawa-Singer M. Trust in one's physician: the role of ethnic match, autonomy, acculturation, and religiosity among Japanese and Japanese Americans. Ann Fam Med 2005;3:339-47.

31. McKinstry B, Wang JX. Putting on the style: what patients think of the way their doctor dresses. Br J Gen Pract 1991;41:275-8.

32. Campbell J, Smith P, Nissen S. Development of the national GP Patient Survey for use in primary care in the National Health Service in the UK. BMC Fam Pract 2009;10:57. doi:10.1186/ 1471-2296-10-57

33. Roland M, Elliott M, Lyratzopoulos G. Reliability of patient responses in pay for performance schemes: analysis of national General Practitioner Patient Survey data in England. BMJ 2009;339:955.

34. Department of communities and local government. The English indices of deprivation [internet] 2007. (updated; cited 16 July 2012). http://www.communities.gov.uk/documents/communities/pdf/ 576659.pdf
35. Elliott MN, Edwards C, Angeles J, et al. Patterns of unit and item nonresponse in the CAHPS hospital survey. Health Serv Res 2005;40:2096-119.

36. Kahn KL, Honhiu L, Adams JL, et al. Methodological challenges associated with patient responses to follow-up longitudinal surveys regarding quality of care. Health Serv Res 2003;38:1579-98.

37. Angus VC, Entwistle VA, Emslie MJ, et al. The requirement for prior consent to participate on survey response rates: a population-based survey in Grampian. BMC Health Serv Res 2003;3:21.

38. Thorne SE, Robinson CA. Guarded alliance: health care relationships in chronic disease. Image J Nurse Sch 1989; 21:153-7.

39. Luhmann N. Familiarity, confidence, trust: problems and alternatives In: Diego G, ed. Trust: making and breaking cooperative relations. Electronic edn. Department of Sociology, University of Oxford, 2000 chapter 6:94-107. http://www.sociology.ox.ac.uk/papers/luhmann94107.pdf (accessed 26 Mar 2013).

40. Gidman W, Ward P, McGregor L. Understanding public trust in services provided by community pharmacists relative to those provided by general practitioners: a qualitative study. BMJ Open 2012;2:e000939.

41. Jalava J. From Norms to Trust. The Luhmannian connections between trust and system. Eur J Soc Theory 2003;6:173-90.

42. Dibben MR, Davies HTO. Trustworthy doctors in confidence building systems. Qual Saf Health Care 2004;13:88-9.

43. Little P, Everitt $H$, Williamson I. Preferences of patients for patient centred approach to consultation in primary care: observational study. BMJ 2001;322:1-7.

44. Skirbekk H, Middlethon AL, Hjortdahl $P$, et al. Mandates of trust in the doctor-patient relationship. Qual Health Res 2011;21:1182-90.

45. Bastiaens HVR, Pavlic P, Raposo DR, et al. Older people's preferences for involvement in their own care: a qualitative study in primary health care in 11 European countries. Patient Educ Couns 2007;68:33-42.

46. Levinson WK, Kuby A, Thisted RA. Not all patients want to participate in decision making. A national study of public preferences. J Gen Intern Med 2005;20:531-5.

47. Joffe S, Manocchia M, Weeks JC. What do patients value in their hospital care? An empirical perspective on autonomy centred bioethics. J Med Ethics 2003;29:103-8.

48. Calnan Mw, Sanford E. Public trust in health care: the system or the doctor? Qual Saf Health Care 2004;13:92-7.

49. UK National Statistics. Topic guide to: Older People [internet] 2012 (Updated 1 Sep 2012; cited 9 Jan 2012). http://www.statistics.gov. uk/hub/population/ageing/older-people 